\title{
A systematic review on randomized controlled trials : Coaching elements of digital services to support chronically ill adolescents during transition of care
}

\section{Tornivuori, Anna}

2020-06

Tornivuori , A , Tuominen , O , Salantera , S \& Kosola , S 2020 , ' A systematic review on randomized controlled trials : Coaching elements of digital services to support chronically ill adolescents during transition of care ' , Journal of Advanced Nursing , vol. 76 , no. 6 , pp. 1293-1306 . https://doi.org/10.1111/jan.14323

http://hdl.handle.net/10138/326377

https://doi.org/10.1111/jan.14323

acceptedVersion

Downloaded from Helda, University of Helsinki institutional repository.

This is an electronic reprint of the original article.

This reprint may differ from the original in pagination and typographic detail.

Please cite the original version. 
This is the peer reviewed version of the following article:

Tornivuori, A, Tuominen, O, Salanterä, S, Kosola, S. A systematic review on randomized controlled trials: Coaching elements of digital services to support chronically ill adolescents during transition of care. J Adv Nurs. 2020; 76: 1293- 1306. https://doi.org/10.1111/jan.14323, which has been published in final form at https://doi.org/10.1111/jan.14323. This article may be used for non-commercial purposes in accordance with Wiley Terms and Conditions for Use of SelfArchived Versions. 


\section{A systematic review on randomized controlled trials: Coaching elements of digital services to support chronically ill adolescents during transition of care.}

TORNIVUORI, Anna, RN, MNSc; TUOMINEN, Outi RN, MNSc; KOSOLA, Silja MD, PhD; SALANTER̈̈, Sanna, RN, PhD.

To be cited as: Tornivuori A, Tuominen O, Salantera S, Kosola S. A systematic review on randomized controlled trials: Coaching elements of digital services to support chronically ill adolescents during transition of care. Journal of Advanced Nursing 2020; 6:1293-1306. 


\section{ABSTRACT}

Aims: To define digital health services that have been studied among chronically ill adolescents and to describe e-health coaching elements that may impact transition outcomes.

Design: Systematic review without meta-analysis.

Data sources: MEDLINE (Ovid), Pub Med, Scopus and CINAHL on May $28^{\text {th }}, 2018$.

Review Methods: Peer-reviewed articles published between January 2008 and May 2018 were reviewed following the Cochrane Handbook for Systematic Reviews of Interventions and reported according to the Preferred Reporting Items for Systematic Reviews and Meta-analyses statement.

Results: Twelve randomised controlled trials were included. The interventions varied significantly in duration and content. E-coaching that included human and social support showed positive impact on transition outcomes. Digital health services incorporated into usual care provide efficient and accessible care.

Conclusion: E-coaching elements enable tailoring and personalization and present a tool for supporting and motivating chronically ill adolescents during transition of care. Future research should evaluate the effectiveness of e-coaching elements.

\section{Impact:}

What problem did the study address?

- Digital health services have developed rapidly. This increases the importance of identifying patient groups who may benefit from particular digital services.

- This study clarifies the e-coaching elements that may positively impact chronically ill adolescents during transition of care.

\section{What were the main findings?}

- Digital services are seen as a means for increasing adolescents' motivation for selfcare and for increasing their accessibility to healthcare.

- The coaching elements in digital services consist of a theoretical basis, human support, interactive means and social support.

- Included interventions varied in terms of duration, dose, content and design.

\section{Where and on whom will the research have impact?}

- Our results may serve the development of digital health services for adolescents in transition.

- E-coaching can be used to engage and motivate chronically ill adolescents to improve health behaviour and self-management during transition of care.

Key words: Chronically ill adolescent, nursing, e-coaching, health coaching, transition of care, digital health services, health-behaviour, systematic review, self-management, support. 


\section{INTRODUCTION}

The number of adolescents and young adults with severe chronic health conditions, whose care is being transferred from children's hospitals to adult healthcare, is growing (Bomba, HerrmannGaritz, Schmidt, Schmidt, \& Thyen, 2017; Morsa, Gagnayre, Deccache, \& Lombrail, 2017). This is in part due to an increase in the incidence of diseases (e.g. diabetes and inflammatory bowel diseases) as well as significant improvements in treatment (e.g. congenital heart defects and cystic fibrosis) (Lehtinen et al., 2011). Chronically ill adolescents often experience more challenges than their healthy peers, including difficulties in socialisation, body image, physical limitations or regression in development and modified daily routines. Research shows that chronically ill adolescents engage in more risk-taking behaviour such as substance abuse, risky sexual behaviour and neglect of care which can have detrimental effects on health (Jacobs \& Popick, 2012; Ssewanyana, Nyongesa, van Baar, Newton, \& Abubakar, 2017). Chronically ill adolescents often experience feelings of not belonging and find it hard to adjust to increased responsibility for their own care when transferred to adult clinics (Crowley, Wolfe, Lock, \& McKee, 2011; Fegran, Hall, Uhrenfeldt, Aagaard, \& Ludvigsen, 2014). Long-term health outcomes of chronic diseases depend on disease awareness, the ability to engage in self-care and motivation to treatment (Zheng et al., 2010).

During transition of care, chronically ill adolescents experience a loss of familiar settings and connections combined with feelings of insecurity and being unprepared for what to expect. Adolescents need support and continuity of care to enable them to take responsibility for their health, to self-manage and to gain independence (Bomba et al., 2017; Fegran et al., 2014). To ensure continued wellbeing and stability in life, a controlled transition process to adult care is vital (Fishman, Mitchell, Lakin, Masciarelli, \& Flier, 2016; Holmberg \& Jalanko, 2016). Within many chronic diseases, poorly prepared transition of care leads to inferior health outcomes in adolescents and young adults (Fegran et al., 2014; Fishman et al., 2016; Johnson et al., 2015). There is a growing need for research concerning chronically ill adolescents and the transition process from children's hospitals to adult sites (Campbell et al., 2016; Ladouceur et al., 2017). Many transition programmes have gaps in both educational content and in meeting the needs of chronically ill adolescents during transition of care (Bomba et al., 2017; Fegran et al., 2014; Fishman et al., 2016; Morsa et al., 2017; Weissberg-Benchell \& Shapiro, 2017). As the use and development of digital services have increased significantly, it is important to find new ways to engage chronically ill adolescents in caring for themselves by using digitalisation in healthcare (Cantrell, Fischer, Bouzaher, \& Bers, 2010; Coyne, Hallowell, \& Thompson, 2017). Since adolescents are active users of the Internet and mobile services, digital health services could potentially be used to provide adolescent-friendly and individualised health care and to improve communication between healthcare providers and adolescents. Communication and supplying information are the core elements in the care of chronically ill adolescents (Beresford \& Sloper, 2003; Sterling, Nyhof-Young, Blanchette, \& Breakey, 2012). E-coaching is a relatively new concept in digital health services which shows promising results in improving communication, 
psychosocial health and promoting positive health outcomes (Veen, Bovendeert, Backx, \& Huisstede, 2017).

A vast amount of digital health services are being developed and youth preferences should be taken into consideration when designing digital services (Radovic, McCarty, Katzman, \& Richardson, 2018). A better understanding of programmes that promote self-management, care motivation and health outcomes of chronically ill adolescents is required to reach better preparedness for transition of care (Bomba et al., 2017).

\section{Background}

Transition of care is an important healthcare issue and may greatly affect the health of chronically ill adolescents. Transition of care is understood as a process that addresses both the preparation before and the experiences after the actual transfer of care from children's hospitals to adult sites (Fegran et al., 2014; Mahan, Betz, Okumura, \& Ferris, 2017; Meleis, 2010). The transition elements which support the transition process include physical health status (Coyne, et al., 2017), health related quality of life (HRQoL) transition readiness, self-management (Suris, \& Akre, 2015), care-motivation and self-efficacy (Johnson et al., 2015; Campbell et al., 2016). Psychosocial health as, for example stress and anxiety, are also to be taken into consideration when assessing transition outcomes (Zhou, Roberts, Dhaliwal, \& Della, 2016). In this study we have used these transition elements to address the transition outcomes in the included studies.

The use of digital services offers accessibility, engages patients to take responsibility and facilitates management of care. It also supports self-care and communication between healthcare professionals and patients (Allen, Iezzoni, Huang, Huang, \& Leveille, 2008; Bickmore, Gruber, \& Picard, 2005; Leveille et al., 2009; Niemi, Hupli, \& Koivunen, 2016). The digitalisation process in healthcare is shifting the patient- provider relationship into a more collaborative and engaging direction. A need remains to understand what impact digital services have on patient/ provider communication and relationships (Weiner, 2012).

E-coaching is designed to change attitudes and behaviour interactively and it emphasises provision of support and instructions on how to complete goals (Ding et al., 2010). E-coaching may improve communication, disease management and social support and motivate chronically ill adolescents to manage their health condition (Jacobs \& Popick, 2012; Leveille et al., 2009). Multicomponent digital health services can provide adolescents with the support they need (Kunin-Batson, Steele, Mertens, \& Neglia, 2016). E-coaching is a rapidly expanding area, which still requires quality criteria, especially in the field of health care (Kamphorst, 2017; Veen et al., 2017). Yet neither the design of e-health coaching programs to match patients' individual needs nor the impact of e-coaching programs has received sufficient attention (Graffigna et al., 2014). 
Coaching has been proven successful in improving communication, engagement, motivation and achieving goals in several different fields, such as sports, psychology, and more recently, also in nursing (Hayes \& Kalmakis, 2007; Olsen, 2014). Coaching approaches the learning process both through behavioural and cognitive features. Behaviour change and empowerment are the key aspects of coaching (Dennis et al., 2013; Fazel, 2013). Health coaching is a relatively new concept that is used widely in health care settings and yet it is only partly defined (Boehmer et al., 2016; Kivela, Elo, Kyngas, \& Kaariainen, 2014; Olsen, 2014; Stevens, Hayes, \& Pakalnis, 2014). Olsen defines health coaching as "a goal-oriented, client-centred partnership that is health-focused and occurs through a process of client enlightenment and empowerment" (Olsen, 2014). Health coaching has had a positive impact on physiological, behavioural, psychological and social outcomes (Kivela et al., 2014). Coaching is a process that includes elements such as a human and social support, interaction via communication, goalsetting, listening and providing feedback (Hayes \& Kalmakis, 2007; Kamphorst, 2017; Palmer, Tubbs, \& Whybrow, 2003). However, these elements are still scarcely studied and vaguely defined.

The mode, delivery, content and processes of digital health services vary greatly, and a wide range of terms are used, such as on-line-, internet-, web-, digital health interventions, e-Health, mHealth and telehealth services to mention a few (Hollis et al., 2017; Veen et al., 2017). In this study, we use digital health services as an overarching term in reference to health interventions delivered through the internet.

Although research around digital health services designed for chronically ill adolescents is rising, great variation still exists in the methods and outcomes used. This study aims to summarise the existing data around digital health services, e-coaching elements and the needs of chronically ill adolescents during the transition of care from children's hospitals to adult sites.

\section{THE REVIEW}

\section{Aims}

Our aim was to conduct a systematic review of current literature to define digital health services that have been studied among chronically ill adolescents and to describe e-health coaching elements that may impact transition outcomes. To achieve these aims the following research questions were formed:

1. What kind of digital health services have been studied among chronically ill adolescents?

2. How has e-health coaching been used in these studies?

3. Which e-health coaching elements are associated with desired transition outcomes among chronically ill adolescents? 


\section{Design}

This systematic review without a meta-analysis was conducted with the support of the Cochrane Handbook for Systematic Reviews of Interventions (Higgins et al., 2019) and reported in accordance with PRISMA (Preferred Reporting for Systematic Review and Meta-Analyses) statement (Moher, Liberati, Tetzlaff, \& Altman, 2009).

\section{Search methods}

A search was conducted in May 2018 in Medline (Ovid), Scopus, CINAHL, and PubMed for relevant research concerning adolescents, e-coaching and transition that had been published between January 2008 and May 2018. The search was done with an information specialist. Articles before 2008 were excluded due to the major development of internet-based health care and digitalisation after that time. The search was conducted using medical subject headings (MESH terms) and closely related words and synonyms for coaching. This resulted in the following search terms: chronically ill adolescents*, transf*, transit*, young*, teen* youth and ecoach*, e-mentor*, e-counsel*, online* coach*, online* counsel*, online* mentor*, web* coach*, web* mentor*, web* counsel*, internet* coach*, internet* counsel*, internet* mentor*, online*, web*, internet* program*, ehealth* ${ }^{*}{ }^{*}{ }^{*}{ }^{*}$, ehealth* ${ }^{*}{ }^{*}{ }^{*}{ }^{*}{ }^{*}$, ehealth* mentor*, mhealth* coach*, mhealth* counsel*, mhealth* mentor* and transit*, transf* to adult care, car*.

The systematic search was complemented manually to ensure comprehensive results. This was done through reference lists of chosen studies (snowballing), and through a manual search using Google and Google scholar with combinations of the search terms mentioned above. An example of a complete search strategy is found as a supplementary table 1 .

\section{Inclusion criteria and study selection}

The studies had to meet all of the following criteria for inclusion in the review:

\section{Population}

Studies that addressed adolescents with a chronic physical disease, who were between the ages of 10 and 25 .

\section{Intervention}

Internet based health interventions, in a digital form, with focus on disease management were included (digital-, online-, internet-, computer- mobile-, intervention-, program or tool. The interventions could also consist of non-digital items).

\section{Comparison}

Control groups either received no digital interventions, or if a control group used digital information, it could not be tailored nor include any coaching elements. 


\section{Outcome}

We gathered information on both transition and coaching elements (health outcomes, HRQoL, self-management, selfcare, care motivation, self-efficacy, social support, coping, transition preparedness, effectiveness or impact, coach, counsel, mentor).

\section{Study design}

We included randomized, controlled or clinical trials, clinical interventions, or clinical studies published between January 2008 and May 2018.

\section{Search outcomes}

The studies were identified by the first reviewer (AT) and discussed thoroughly with a second reviewer (OT). After removing duplicates, all the remaining studies were screened by title. Potentially eligible titles lead to reading of the abstract. The studies that seemed potentially eligible were included in the full text review. Full texts were read by two reviewers (AT, OT) and checked to match the eligibility criteria and included in the final review through consensus (AT, OT).

\section{Quality appraisal}

The risk of bias in individual studies at study level was independently assessed by two reviewers (AT, OT). The Cochrane risk of bias tool for EPOC reviews, randomized controlled trials was used, appraising nine domains: random sequence generation, allocation concealment, similarity of baseline outcome measurement and characteristics, incomplete outcome data, blinding, protection against contamination, selective outcome reporting and other risk of bias. For all of the nine domains a critical appraisal of possible bias was made and assigned into one of three categories: low risk of bias, high risk of bias and unclear risk of bias (Epoc.cochrane.org). A table summarising the appraisal of risk of bias is found as supplementary table 2 . The reasons for reaching the given categories is found as supplementary table 3. The appraisal was done separately by two reviewers (AT and OT). In cases of disagreement consensus was reached through discussion. Most information from included studies was assessed as low or unclear risk of bias (Higgins et al., 2011).

\section{Data abstraction and synthesis}

Data abstraction was conducted mainly by the primary reviewer (AT) but discussed with the second reviewer (OT). The template for intervention description and replication (TIDieR) checklist and guide was adapted for extracting the data (Hoffmann et al., 2014). The data extraction followed three phases. First, the characteristics of the data were extracted from eligible studies, including brief name, duration and amount of sessions, who and how the interventions were provided. Secondly, the characteristics of the interventions were extracted according to country, target population/ diagnoses, age and sample size, outcome measurement and main result. Thirdly, statistical data on transition elements were identified and listed to get 
an understanding of the effects of the outcomes in the included studies. Furthermore, the data on coaching and transition elements was presented with a narrative synthesis (Grant \& Booth, 2009). Due to differences in methods and outcome measures in the included studies, a metaanalysis of the results was not applicable.

The transition elements were recognized through careful analysis of the characteristics of the interventions and then entered into two tables to help us reach an understanding of the usage and the effectiveness of these in the included studies. The Grade of Recommendations Assessment, Development and Evaluation (GRADE) was used to evaluate the certainty of the evidence of the transition outcomes. The certainty of the evidence was assessed in the following domains: limitations of study design, inconsistency, indirectness, imprecision and publication bias. According to the GRADE criteria, the certainty of the evidence for the transition outcomes was estimated from moderate to low (Schünemann, Brožek, Guyatt, \& Oxman, 2013) (Table 1). For the coaching elements, data was drawn in three phases. First, relevant coaching actions and synonyms were identified, second, elements were pooled into themes and finally, they were categorized under four domains: human support, interactive means, social support and theoretical bases. We only addressed the transition elements with the GRADE tool because the e-coaching elements are still partly undefined and used with great variety in digital health care interventions.

\section{RESULTS}

After the process of removing duplicates, title and abstract screening, reviewing of full text, quality assessment and appraisal of bias, 12 studies remained. The included studies were randomised, controlled trials comprising digital interventions for chronically ill adolescents (Figure 1 Prisma flowchart).

\section{Digital health services for chronically ill adolescents}

All of the interventions had an educational aim, with differing combinations of information and skills training modules that targeted health outcomes. The interventions were tailored and delivered in several ways from using face to face contact through skype, to communicating by different interactive message-modules on secure web-bases. The duration of the interventions varied from 6 weeks to one study being conducted over two years. Some studies included parents and some peers. The main characteristics of the intervention are collated in table 2.

The twelve included studies were randomised, controlled trials published between 2010-2017 from Europe (4 studies), USA (4 studies), Canada (3 studies) and Australia (1 study). The studies covered several different chronic physical conditions: asthma (3 studies), type 1 diabetes (3 studies), juvenile idiopathic arthritis (3 studies), haemophilia (1 study), inflammatory bowel disease ( 1 study) and one study across several diagnoses, namely cystic fibrosis, type 1 diabetes and inflammatory bowel disease. The participants' ages varied between 10 and 25 years. The sample sizes also varied greatly from 29 up to 422 participants. The aim of the studies mainly 
focused on evaluation or examination of feasibility and effectiveness of digital interventions. The most frequent outcome measurements of the included studies were disease specific outcomes and measurements of HRQoL (The main characteristics of the studies see supplementary table 4).

\section{The use of e-health coaching in the included studies}

Through the analysis of the included studies the different health-coaching means were grouped into four elements: human support, interactive means, social support and theoretical basis. These E-coaching elements and usage of these are presented in table 3.

\section{Human support}

The qualifications of the coaches differed from healthcare professionals to trained peers and the coaching sessions varied in length and duration. The role of the coach was to function as a motivator and supporter and to enable the interactivity of the interventions. Either by active sessions through skype or telephone (Ammerlaan et al., 2017; Freeman, Duke, \& Harris, 2013; Harris, Freeman, \& Duke, 2015; Stinson et al., 2016) or online through chats and educational modules (Breakey et al., 2014; Huang et al., 2014; Joseph et al., 2013; Newcombe et al., 2012; Rikkers-Mutsaerts et al., 2012; Stinson et al., 2010). In one study the human support was available by self-directed communication (Hanberger, Ludvigsson, \& Nordfeldt, 2013), this study had a low engagement with adolescents, implying that an engaging coaching role could be more efficient. In five studies there was a designated coach, mentor or referral coordinator in charge of the intervention with additional support from the healthcare team (Ammerlaan et al., 2017; Breakey et al., 2014; Joseph et al., 2013; Stinson et al., 2010, 2016). Apart from providing online support, the coach planned and assisted in making goals, promoted communication, and encouraged and motivated the participants. To optimise time usage and make the treatment more equal, standardised scripts were used (Bonnert et al. 2017; Breakey et al., 2014; Joseph et al., 2013; Stinson et al., 2010) (see table 3).

\section{Interactive means}

Communication through skype, telephone, written assignments, games and quizzes were used as interactive means. Audio, video and graphics promoted interactivity (Ammerlaan et al., 2017; Bonnert et al., 2017; Breakey et al., 2014; Hanberger et al., 2013; Joseph et al., 2013; Newcombe et al., 2012; Rikkers-Mutsaerts et al., 2012.) Tailored content such as computer algorithms that reacted to adolescents' answers or ethnically diverse characters, personalised, customised and allowed individual guidance (Joseph et al., 2013; Rikkers-Mutsaerts et al., 2012) to make the service more attractive for the adolescents to use. Voiceovers, for example a radio disc jockey delivering advice, were used to engage and to accommodate for limitations in literacy (Joseph et al., 2013). Also focus on effective communication regarding difficult subjects and adherence to treatment was addressed in several studies (Ammerlaan et al., 2017; Breakey et al., 2014; Hanberger et al., 2013; Harris et al., 2015; Joseph et al., 2013; Newcombe et al., 2012; RikkersMutsaerts et al., 2012; Stinson et al., 2010, 2016) (see table 3). 


\section{Social support}

Social support is an integral factor for self-management and care motivation and was addressed through discussion boards and blog modules (Ammerlaan et al., 2017; Breakey et al., 2014; Hanberger et al., 2013; Huang et al., 2014; Newcombe et al., 2012; Stinson et al., 2010, 2016). Peer support was shown to be a very beneficial factor (Ammerlaan et al., 2017; Breakey et al., 2014; Huang et al., 2014; Newcombe et al., 2012; Stinson et al., 2010, 2016) and including parents and family showed positive results (Bonnert et al., 2017; Freeman et al., 2013; Hanberger et al., 2013; Harris et al., 2015; Newcombe et al., 2012; Stinson et al., 2010, 2016) (see table 3).

\section{Theoretical basis}

The included studies were based on behavioural, cognitive and psychoeducational theories. The theory-based strategies (Ammerlaan et al., 2017; Bonnert et al., 2017; Freeman et al., 2013; Hanberger et al., 2013; Harris et al., 2015; Huang et al., 2014; Joseph et al., 2013; Newcombe et al., 2012; Rikkers-Mutsaerts et al., 2012) aimed for behaviour change, supporting selfmanagement and motivation. Only three studies stated no theoretical background although the aim was similar as in theory-based interventions (Breakey et al., 2014; Stinson et al., 2010, 2016) (see table 3).

\section{Transition elements of the included studies}

The transition elements are presented in table 3 to clarify which elements were addressed in which of the selected studies. The statistical data of the transition elements are collated in supplementary table 5. All of the studies measured a positive or equal effect on health outcomes there was either an increase or no difference compared to the intervention groups. None showed a deterioration in health outcomes after the digital intervention. In two studies the number of sessions adhered to positive health outcomes (Freeman et al., 2013; Hanberger et al., 2013). Four studies had a transitional theme as part of the intervention (Ammerlaan et al., 2017; Breakey et al., 2014; Huang et al., 2014; Stinson et al., 2016). Transition preparedness was measured in two of these studies (Breakey et al., 2014; Huang et al., 2014). Both studies showed a positive increase in transition preparedness for the intervention group compared to the control group. Disease specific knowledge (Breakey et al., 2014; Sinson et al., 2010) self-efficacy (Huang et al., 2014; Breakey et al., 2014) self -management (Stinson et al., 2016) and problem solving (Newcombe et al., 2012) increased for the intervention groups. Significant improvement in quality of life and reduced disease symptoms showed in three studies (Bonnert et al., 2017; Rikkert-Mutsaerts et al., 2012, Joseph et al., 2013). (see table 3 and for statistical data supplementary table 5).

\section{E coaching elements associated with transition outcomes}

The human support factor facilitated and enabled adolescents to reach their personal health goals. Through the digital tool the interaction between peers, coach and family was made accessible, 
and the coaches engaging factor was of great importance. Care motivation and self-management were supported by disease specific information, educational videos, and easily accessible healthcare providers and coaches (Ammerlaan et al., 2017; Breakey et al., 2014; Stinson et al., 2010, 2016). The learning experience and usability of the internet interventions were measured mostly by page hits or as qualitative patient reported outcomes. The educational themes, learning experiences and usability were greatly valued and the interactive elements highly appreciated (Ammerlaan et al., 2017; Bonnert et al., 2017; Breakey et al., 2014; Huang et al., 2014; Joseph et al., 2012; Newcombe et al., 2012; Rikkers-Mutsaerts et al., 2012; Stinson et al., 2010, 2016). Two studies (Bonnert et al. 2017; Joseph et al., 2013) showed decrease in school absence compared to the intervention group. A digital service alone seemed insufficient; reminders, incentives and feedback motivated and engaged adolescents to reach better health outcomes, through independence and situational understanding.

\section{DISCUSSION}

This review describes and compares digital health services for chronically ill adolescents and aims to define the e-coaching elements that are associated with positive transition outcomes. Coaching support is an essential aspect of digital programs because it improves motivation, supports self -management and thus promotes transition outcomes. The results of this study indicate that active participation in communication with coaches and peers had a positive impact on transition outcomes.

Psycho-educational digital interventions have shown improvements in health behaviour, problem solving and self-management in the care of chronically ill adolescents (Grey et al., 2013; Palermo et al., 2016; Whittemore et al., 2016). This study shows that coaching elements activate adolescents to promote health behaviour and improve the psycho-educational aspect of the digital health services. To enhance the educational aspects the role of the online coach, highlighting of news, alerts and reminders of postings are central. Digital e-coaching services need to address the psychological adaptation to a chronic illness, be holistic and meet the unique needs of chronically ill adolescents.

Many digital platforms compete for adolescents' attention every day. For a health coaching intervention to be attractive, it needs to be personalised to adolescents' needs. Multicomponent interventions show more potential to engage adolescents than solely educational interventions (Kunin-Batson et al., 2016; Palermo et al., 2016). The interactive educational elements such as audio, video and graphics increased the usability and acceptance of the included digital health interventions. Also, the tailored content boosted user friendliness and accommodated, for example, literary limitations. In a virtual world, gamification techniques such as avatars and ecoaches both play a powerful role in engaging participants (Cantrell et al., 2010; Hieftje, Edelman, Camenga, \& Fiellin, 2013; LeRouge, Dickhut, Lisetti, Sangameswaran, \& Malasanos, 2016). 
Chronically ill adolescents need tools that engage and challenge them to take charge of their own health. Digital health services have the potential to promote and support adolescents due to the neutral settings the interacting possibilities that they offer (Cantrell et al., 2010; Beaudry, Consigli, Clark, \& Robinson 2019). Furthermore, sensitive subjects that are important to adolescents need to be addressed. Information about subjects such as contraception, sexuality, risk taking behaviour, and drugs and alcohol should to be available to meet the adolescents' needs.

More research is needed to define who benefits most from digital health services and how much online coaching support is needed for digital health services to be most effective (Aschbrenner, Naslund, Tomlinson, Kinney, Pratt and Brunette 2019; Hollis et al., 2017; Sehlin, Ahlström, Andersson, \& Wentz, 2018).

\section{Limitations}

Our review has some limitations. The novelty of digital health services in the care of chronically ill adolescents and the scarcity of studies on e-coaching resulted in a highly varied search result. As the included randomised controlled trials were mostly of small samples and had heterogeneous delivery, it was impossible to draw comprehensive conclusions and to conduct a meta-analysis.

While assessing risk of bias some concerns about the ninth domain (other risk of bias) were discussed at length. In some studies, participants received either monetary or other incentives during the intervention. Both researchers (AT and OT) contemplated compensation as an ethical issue since it was impossible to discern if compensation lead to more eager participation and more positive results. It was unclear when the incentives were given, by whom and under what circumstances. We considered this an unclear risk of bias. Incomplete blinding and insufficient information about protection of contamination were assessed as unclear risk of bias across studies. These potential limitations were considered unlikely to lower the confidence in the estimate of results. We did not address certainty of the evidence on care motivation with the GRADE tool, because of large variance of outcomes; both narrative reporting and differing measurement tools.

\section{CONCLUSION}

Tailored digital health services for chronically ill adolescents have positive effects on health outcomes and show great potential to develop care during transition from children's hospitals to adult sites. The results of this review suggest that digital health services as part of usual care have a positive impact on health outcomes and that personal goalsetting and active participation in communication with coach and peers have a positive impact on transition outcomes. 
To date, the development of e-coaching is not yet systematic, and it is important to identify the ecoaching elements. By identifying the elements, we can translate the individual phenomena into a measurable form and evaluate its real impact on the transition process. The results show that although there are many e-coaching programs available, only a few of them have been studied in clinical trials and the studies are not easy to compare with each other from the perspective of outcomes. The lack of consistent and long-term studies on e-coaching in digital health services, suggests that more rigorous research on the efficacy of coaching elements is needed

The coaching elements that were identified in this review were; need for human support, interactive means, social support and theoretical basis. These elements should be taken into consideration when new e-coaching programs are developed.

Although we could identify some elements that are relevant for e-coaching, there is still scarce evidence on how the elements should be used in programs and platforms. Evidence on the dose of human support and how the theory should be implemented is needed. Also, there needs to be more research into what the best and most effective ways of interaction are and how to use social support so that it is supporting the transitions process to adult care and independency.

The challenge in health care is that chronically ill adolescents are not properly prepared for independence and - on the brink of adulthood they are suddenly expected to successfully selfmanage and take care of their health. E-coaching could be a solution for supporting selfmanagement, but still we don't know if it is efficacious and which of the e-coaching elements should be considered. Through this study, we were able to identify some of the elements that seem to be related to the quality of life, self-management and promotion of a young person's health behaviour and health outcomes. The findings of this study imply that digital health services, with coaching elements, are an important complement to the often fragmented care path of chronically ill adolescents during the transition of care.

\section{Conflict of Interest statement}

No conflict of interest has been declared by the authors. 


\section{References}

Allen, M., Iezzoni, L. I., Huang, A., Huang, L., \& Leveille, S. G. (2008). Improving patientclinician communication about chronic conditions: description of an internet-based nurse E-coach intervention. Nursing Research, 57(2), 107-112. doi:10.1097/01.NNR.0000313478.47379.98

Ammerlaan, J., van Os-Medendorp, H., de Boer-Nijhof, N., Scholtus, L., Kruize, A., van Pelt, P.,...Bijlsma, H. (2017). Short term effectiveness and experiences of a peer guided webbased self-management intervention for young adults with juvenile idiopathic arthritis. Pediatric Rheumatology Online Journal, 15(1), 75. doi:10.1186/s12969-017-0201-1

Aschbrenner, K., Naslund, A., Tomlinson, E., Kinney, A., Prat, S., \& Brunette, M. 2019. Adolescent's use of digital technologies and preferences for mobile health coaching in public mental health settings. Front public health 7 (178). doi: 10.3389/fpubh.2019.00178.

Beaudry, J., Consigli, A., Clark, C. \& Robinson K. (2019) Getting ready for adult health care:

Designing a chat bot to coach adolescents with special health needs through the transition of care. Journal of pediatric nursing 4985-91. doi. org/10.1016/j.pedn2019.09.004

Beresford, B. A., \& Sloper, P. (2003). Chronically ill adolescents' experiences of communicating with doctors: A qualitative study. Journal of Adolescent Health, 33(3), 172-179. doi:10.1016/S1054-139X(03)00047-8

Bickmore, T., Gruber, A., \& Picard, R. (2005). Establishing the computer-patient working alliance in automated health behavior change interventions. Patient Education and Counseling, 59(1), 21-30. doi:10.1016/j.pec.2004.09.008

Boehmer, K. R., Barakat, S., Ahn, S., Prokop, L. J., Erwin, P. J., \& Murad, M. H. (2016). Health coaching interventions for persons with chronic conditions: A systematic review and meta-analysis protocol. Systematic Reviews, 5(1), 146. doi:10.1186/s13643-016-0316-3

Bomba, F., Herrmann-Garitz, C., Schmidt, J., Schmidt, S., \& Thyen, U. (2017). An assessment of the experiences and needs of adolescents with chronic conditions in transitional care: a qualitative study to develop a patient education programme. Health and Social Care in the Community, 25(2), 652-666. doi:10.1111/hsc.12356

Bonnert, M., Olén, O., Laloni, M., Benninga, B., Bottai, M., Engelbrektsson, M.,...Ljótsson, B. (2017). Internet-delivered cognitive behavior therapy for adolescents with irritable bowel syndrome: A randomized controlled trial. American Journal of Gastroenterology, 112(1), 152-162. doi:10.1038/ajg.2016.503

Breakey, V., Ignas, D., Warias, A., White, M., Blanchette, V., \& Stinson, J. (2014). A pilot randomized control trial to evaluate the feasibility of an internet-based self-management and transitional care program for youth with haemophilia. Haemophilia, 20(6), 784-793. doi:10.1111/hae.12488

Campbell, F., Biggs, K., Aldiss, S. K., O’Neill, P. M., Clowes, M., McDonagh, J., \& Gibson, F. (2016). Transition of care for adolescents from paediatric services to adult health services (Review). Cochrane Database of Systematic Reviews, 4, CD009794. doi:10.1002/14651858.CD009794.pub2 
Cantrell, K., Fischer, A., Bouzaher, A., \& Bers, M. (2010). The role of E-mentorship in a virtual world for youth transplant recipients. Journal of Pediatric Oncology Nursing, 27(6), 344355. doi:10.1177/1043454210372617

Cochrane Effective Practice and Organisation of Care (EPOC). (2017). EPOC resources for review authors. Retrieved from epoc.cochrene.org/epoc-resources-review-authors

Coyne, B., Hallowell, S. C., \& Thompson, M. (2017). Measurable outcomes after transfer from pediatric to adult providers in youth with chronic illness. Journal of Adolescent Health, 60(1), 3-16. doi:10.1016/j.jadohealth.2016.07.006

Crowley, R., Wolfe, I., Lock, K., \& McKee, M. (2011). Improving the transition between paediatric and adult healthcare: A systematic review. Archives of Disease in Childhood, 96(6), 548-553. doi:10.1136/adc.2010.202473

Dennis, S., Harris, M., Lloyd, J., Powell Davies, G., Faruqi, N., \& Zwar, N. (2013). Do people with existing chronic conditions benefit from telephone coaching? A rapid review. Australian Health Review, 37(3), 381-388. doi:10.1071/AH13005

Ding, D., Liu, H.-Y., Cooper, R., Cooper, R. A., Smailagic, A., \& Siewiorek, D. (2010). Virtual coach technology for supporting self-care. Physical Medicine and Rehabilitation Clinics of North America, 21(1), 179-194. doi:10.1016/j.pmr.2009.07.012

Fazel, P. (2013). Learning theories within coaching process. International Journal of Psychological and Behavioral Sciences, 7(8), 2343-2349. doi.org/10.5281/zenodo.1086709

Fegran, L., Hall, E. O. C., Uhrenfeldt, L., Aagaard, H., \& Ludvigsen, M. S. (2014). Adolescents' and young adults' transition experiences when transferring from paediatric to adult care: A qualitative metasynthesis. International Journal of Nursing Studies, 51(1), 123-135. doi:10.1016/j.ijnurstu.2013.02.001

Fishman, L. N., Mitchell, P. D., Lakin, P. R., Masciarelli, L., \& Flier, S. N. (2016). Are expectations too high for transitioning adolescents with inflammatory bowel disease? examining adult medication knowledge and self-management skills. Journal of Pediatric Gastroenterology and Nutrition, 63(5), 494-499. doi:10.1097/MPG.0000000000001299

Freeman, K., Duke, D., \& Harris, M. (2013). Behavioral health care for adolescents with poorly controlled diabetes via skype: Does working alliance remain intact? Journal of Diabetes Science and Technology, 7(3), 727-735. doi:10.1177/193229681300700318

Graffigna, G., Barello, S., Triberti, S., Wiederhold, B. K., Bosio, A. C., \& Riva, G. (2014). Enabling ehealth as a pathway for patient engagement: A toolkit for medical practice. Studies in Health Technology and Informatics, 199, 13-21. doi.org/10.3233/978-1-61499-401-5-13

Grant, A., \& Booth, A. (2009). A typology of reviews: an analysis of 14 review types and associated methodologies. Health Information and Libraries Journal, 26(2), 91-108. doi:10.1111/j.1471-1842.2009.00848.x 
Grey, M., Whittemore, R., Jeon, S., Murphy, K., Faulkner, M. S., \& Delamater, A.; TeenCope Study Group. (2013). Internet Psycho-Education Programs improve outcomes in youth with type 1 diabetes. Diabetes Care, 36(9), 2475-2482. doi:10.2337/dc12-2199

Hanberger, L., Ludvigsson, J., \& Nordfeldt, S. (2013). Use of a web 2.0 portal to improve education and communication in young patients with families: Randomized controlled trial. Journal of Medical Internet Research, 15(8), e175. doi:10.2196/jmir.2425

Harris, M., Freeman, K., \& Duke, D. (2015) Seeing is believing: Using Skype to improve diabetes outcomes in youth. Diabetes Care, 38(8), 1427-1434. doi:10.2337/dc14-2469

Hayes, E., \& Kalmakis, K. A. (2007). From the sidelines: Coaching as a nurse practitioner strategy for improving health outcomes. Journal of the American Academy of Nurse Practitioners, 19(11), 555-562. doi:10.1111/j.1745-7599.2007.00264.x

Hieftje, K., Edelman, E. J., Camenga, D. R., \& Fiellin, L. E. (2013). Electronic media-based health interventions promoting behavior change in youth: A systematic review. JAMA Pediatrics, 167(6), 574-580. doi:10.1001/jamapediatrics.2013.1095

Higgins, J. P. T., Altman, D. G., Gøtzsche, P. C., Jüni, P., Moher, D., Oxman, A. D.,...Sterne, J. A. C.; Cochrane Bias Methods Group \& Cochrane Statistical Methods Group. (2011). The Cochrane Collaboration's tool for assessing risk of bias in randomised trials. $B M J$, 343, d5928. doi:10.1136/bmj.d5928

Higgins, J. P. T., Thomas, J., Chandler, J., Cumpston, M., Li, T., Page, M. J., \& Welch, V. A. (Eds.). (updated July 2019). Cochrane Handbook for Systematic Reviews of Interventions version 6.0. Cochrane, 2019. Retrieved from www.training.cochrane.org/handbook

Hoffmann, T. C., Glasziou, P. P., Boutron, I., Milne, R., Perera, R., Moher, D.,...Michie, S. (2014). Better reporting of interventions: Template for intervention description and replication (TIDieR) checklist and guide. BMJ, 348, g1687. doi:10.1136/bmj.g1687

Hollis, C., Falconer, C. J., Martin, J. L., Whittington, C., Stockton, S., Glazebrook, C., \& Davies, E. B. (2017). Annual research review: Digital health interventions for children and young people with mental health problems - A systematic and meta-review. Journal of Child Psychology and Psychiatry and Allied Disciplines, 58(4), 474-503. doi:10.1111/jcpp.12663

Holmberg, C., \& Jalanko, H. (2016). Long-term effects of paediatric kidney transplantation. Nature Reviews Nephrology, 12(5), 301-311. doi:10.1038/nrneph.2015.197

Huang, J., Terrones, L., Tompane, T., Dillon, L., Pian, M., Gottchalk, M.,...Batholomew, K. (2014). Preparing adolescents with chronic disease for transition to adult care: A technology program. Pediatrics, 133(6), 1639-1646. doi:10.1542/peds.2013-2830

Jacobs, H. S., \& Popick, R. (2012). Utilization of internet resources for adolescents coping with chronic conditions. Pediatric Nursing, 38(4), 228-31, 235. Retrieved from https://search.proquest.com/docview/1037681302? accountid=14774

Johnson, M. A. J., Javalkar, K., van Tilburg, M., Haberman, C., Rak, E., \& Ferris, M. E. (2015). The relationship of transition readiness, self-efficacy, and adherence to preferred health 
learning method by youths with chronic conditions. Journal of Pediatric Nursing, 30(5), 83-90. doi:10.1016/j.pedn.2015.05.014

Joseph, C., Ownby, D., Havstad, S., Saltzgaber, J., Considine, S., Johnson, D.,...Johnson, C. (2013). Evaluation of a web-based asthma management intervention program for urban teenagers: Reaching the hard to reach. Journal of Adolescent Health, 52(4), 419-426. doi:10.1016/j.jadohealth.2012.07.009

Kamphorst, B. A. (2017). E-coaching systems: What they are, and what they aren't. Personal and Ubiquitous Computing, 21(4), 625-632. doi:10.1007/s00779-017-1020-6

Kivela, K., Elo, S., Kyngas, H., \& Kaariainen, M. (2014). The effects of health coaching on adult patients with chronic diseases: A systematic review. Patient Education and Counseling, 97(2), 147-157. doi:10.1016/j.pec.2014.07.026

Kunin-Batson, A., Steele, J., Mertens, A., \& Neglia, J. P. (2016). A randomized controlled pilot trial of a Web-based resource to improve cancer knowledge in adolescent and young adult survivors of childhood cancer. Psycho-oncology, 25(11), 1308-1316. doi:10.1002/pon.3956

Ladouceur, M., Calderon, J., Traore, M., Cheurfi, R., Pagnon, C., Khraiche, D.,...Bonnet, D. (2017). Educational needs of adolescents with congenital heart disease: Impact of a transition intervention programme. Archives of Cardiovascular Diseases, 110(5), 317324. doi:10.1016/j.acvd.2017.02.001

Lehtinen, P., Ashorn, M., Iltanen, S., Jauhola, R., Jauhonen, P., Kolho, K. L., \& Auvinen, A. (2011). Incidence trends of pediatric inflammatory bowel disease in Finland, 1987-2003, a nationwide study. Inflammatory Bowel Diseases, 17(8), 1778-1783. doi:10.1002/ibd.21550

LeRouge, C., Dickhut, K., Lisetti, C., Sangameswaran, S., \& Malasanos, T. (2016). Engaging adolescents in a computer-based weight management program: Avatars and virtual coaches could help. Journal of the American Medical Informatics Association, 23(1), 1928. doi:10.1093/jamia/ocv078

Leveille, S. G., Huang, A., Tsai, S. B., Allen, M., Weingart, S. N., \& Iezzoni, L. I. (2009). Health coaching via an internet portal for primary care patients with chronic conditions: A randomized controlled trial. Medical Care, 47(1), 41-47. doi:10.1097/MLR.0b013e3181844dd0

Mahan, J. D., Betz, C. L., Okumura, M. J., \& Ferris, M. E. (2017). Self-management and transition to adult health care in adolescents and young adults: A team process. Pediatrics in Review, 38(7), 305-319. doi:10.1542/pir.2016-0074

Meleis, A. I. (2010). Transitions theory: Middle range and situation specific theories in nursing research and practice. Springer Publishing Company, New York.

Moher, D., Liberati, A., Tetzlaff, J., \& Altman, D. G.; PRISMA Group. (2009). Preferred reporting items for systematic reviews and meta-analyses: The PRISMA statement. PLoS Medicine, 6(7), e1000097. doi:10.1371/journal.pmed.1000097 
Morsa, M., Gagnayre, R., Deccache, C., \& Lombrail, P. (2017). Factors influencing the transition from pediatric to adult care: A scoping review of the literature to conceptualize a relevant education program. Patient Education and Counseling, 100(10), 1796-1806. doi:10.1016/j.pec.2017.05.024

Newcombe, P., Dunn, T., Casey, L., Sheffield, J., Petsky, H., Anderson-James, S., \& Chang, A. (2012). Breathe easier online: Evaluation of a randomized controlled pilot trial of an internet based intervention to improve well-being in children and adolescents with a chronic respiratory condition. Journal of Medical Internet Research, 14(1), e23. doi:10.2196/jmir.1997

Niemi, A., Hupli, M., \& Koivunen, M. (2016). The use of electronic communication for patientprofessional interaction - Nursing staff's point of view. Finjehew Finnish Journal of eHealth and eWelfare, 8(4), 200-215. Retrieved from https://journal.fi/finjehew/article/view/60197

Olsen, J. M. (2014). Health coaching: A concept analysis. Nursing Forum, 49(1), 18-29. doi:10.1111/nuf.12042

Palermo, T. M., Law, E. F., Fales, J., Bromberg, M. H., Jessen-Fiddick, T., \& Tai, G. (2016). Internet-delivered cognitive-behavioral treatment for adolescents with chronic pain and their parents: A randomized controlled multicenter trial. Pain, 157(1), 174-185. doi:10.1097/j.pain.0000000000000348

Palmer, S., Tubbs, I., \& Whybrow, A. (2003). Health coaching to facilitate the promotion of healthy behaviour and achievement of health-related goals. International Journal of Health Promotion and Education, 41(3), 91-93. doi:10.1080/14635240.2003.10806231

Radovic, A., McCarty, C. A., Katzman, K., \& Richardson, L. P. (2018). Adolescents' perspectives on using technology for health: Qualitative study. JMIR Pediatrics and Parenting, 1(1), e2. doi:10.2196/pediatrics.8677

Rikkers-Mutsaerts, E., Winters, A., Bakker, M., van Stel, H., van der Meer, V., de Jongste, J., \& Sont, J.; SMASHING study group. (2012). Internet-based self-management compared with usual care in adolescents with asthma: A randomized controlled trial. Pediatric Pulmonology, 47(12), 1170-1179. doi:10.1002/ppul.22575

Schünemann, H., Brožek, J., Guyatt, G., \& Oxman, A. (2013). GRADE handbook. Handbook for grading the quality of evidence and the strength of recommendations using the GRADE approach. Retrieved from https://raining.cochrane.org/resource/grade-handbook

Sehlin, H., Ahlström, B., Andersson, G., \& Wentz, E. (2018). Experiences of an internet-based support and coaching model for adolescents and young adults with ADHD and autism spectrum disorder- A qualitative study. BMC Psychiatry, 18, 15. doi:10.1186/s12888018-1599-9

Ssewanyana, D., Nyongesa, M. K., van Baar, A., Newton, C. R., \& Abubakar, A. (2017). Health risk behavior among chronically ill adolescents: A systematic review of assessment tools. Child and Adolescent Psychiatry and Mental Health, 11(1), 1-17. doi:10.1186/s13034017-0172-5. 
Sterling, L., Nyhof-Young, J., Blanchette, V. S., \& Breakey, V. R. (2012). Exploring internet needs and use among adolescents with haemophilia: A website development project. Haemophilia, 18(2), 216-221. doi:10.1111/j.1365-2516.2011.02613.x

Stevens, J., Hayes, J., \& Pakalnis, A. (2014). A randomized trial of telephone-based motivational interviewing for adolescent chronic headache with medication overuse. Cephalalgia, 34(6), 446-454. doi:10.1177/0333102413515336

Stinson, J., Ahola Kohut, L., Forgeron, P., Amaria, K., Bell, M., Kaufman, M.,...Spiegel, L. (2016). The iPeer2Peer program: A pilot randomized controlled trial in adolescents with juvenile idiopathic arthritis. Pediatric Rheumatology Online Journal, 14(1), 48. doi:10.1186/s12969-016-0108-2

Stinson, J., McGrath, P., Hodnett, E., Feldman, B., Duffy, C., Huber, A.,...White, M. (2010). An Internet-based self-management program with telephone support for adolescents with arthritis: A pilot randomized controlled trial. The Journal of Rheumatology, 37(9), 19441952. doi:10.3899/jrheum.091327

Suris, J. C., \& Akre, C. (2015). Key elements for, and indicators of, a successful transition: An international Delphi study. Journal of Adolescent Health, 56(6), 612-618. doi:10.1016/j.jadohealth.2015.02.007

Veen, E. V., Bovendeert, J. F. M., Backx, F. J. G., \& Huisstede, B. M. A. (2017). E-coaching: New future for cardiac rehabilitation? A systematic review. Patient Education and Counseling, 100(12), 2218-2230. doi:10.1016/j.pec.2017.04.017

Weiner, J. P. (2012). Doctor-patient communication in the e-health era. Israel Journal of Health Policy Research, 1(1), 33. doi:10.1186/2045-4015-1-33

Weissberg-Benchell, J., \& Shapiro, J. B. (2017). A review of interventions aimed at facilitating successful transition planning and transfer to adult care among youth with chronic illness. Pediatric Annals, 46(5), e182-e187. doi:10.3928/19382359-20170421-01

Whittemore, R., Liberti, L. S., Jeon, S., Chao, A., Minges, K. E., Murphy, K., \& Grey, M. (2016). Efficacy and implementation of an Internet psychoeducational program for teens with type 1 diabetes. Pediatric Diabetes, 17(8), 567-575. doi:10.1111/pedi.12338

Zheng, K., Newman, M. W., Veinot, T. C., Hanratty, M., Kim, H., Meadowbrooke, C., \& Perry, E. E. (2010). Using online peer-mentoring to empower young adults with end-stage renal disease: A feasibility study. AMIA. Annual Symposium Proceedings. AMIA Symposium, 942-946. Retrieved from http://ovidsp.ovid.com/ovidweb.cgi?T=JS\&PAGE $=$ reference $\& D=$ med6\&NEWS $=$ N\&AN $=21347117$

Zhou, H., Roberts, P., Dhaliwal, S., \& Della, P. (2016). Transitioning adolescent and young adults with chronic disease and/or disabilities from paediatric to adult care services- An integrative review. Journal of Clinical Nursing, 25(21-22), 3113-3130. doi:10.1111/jocn.13326 
Figure 1. PRISMA flow diagram of the study selection process (Moher et al. 2009)
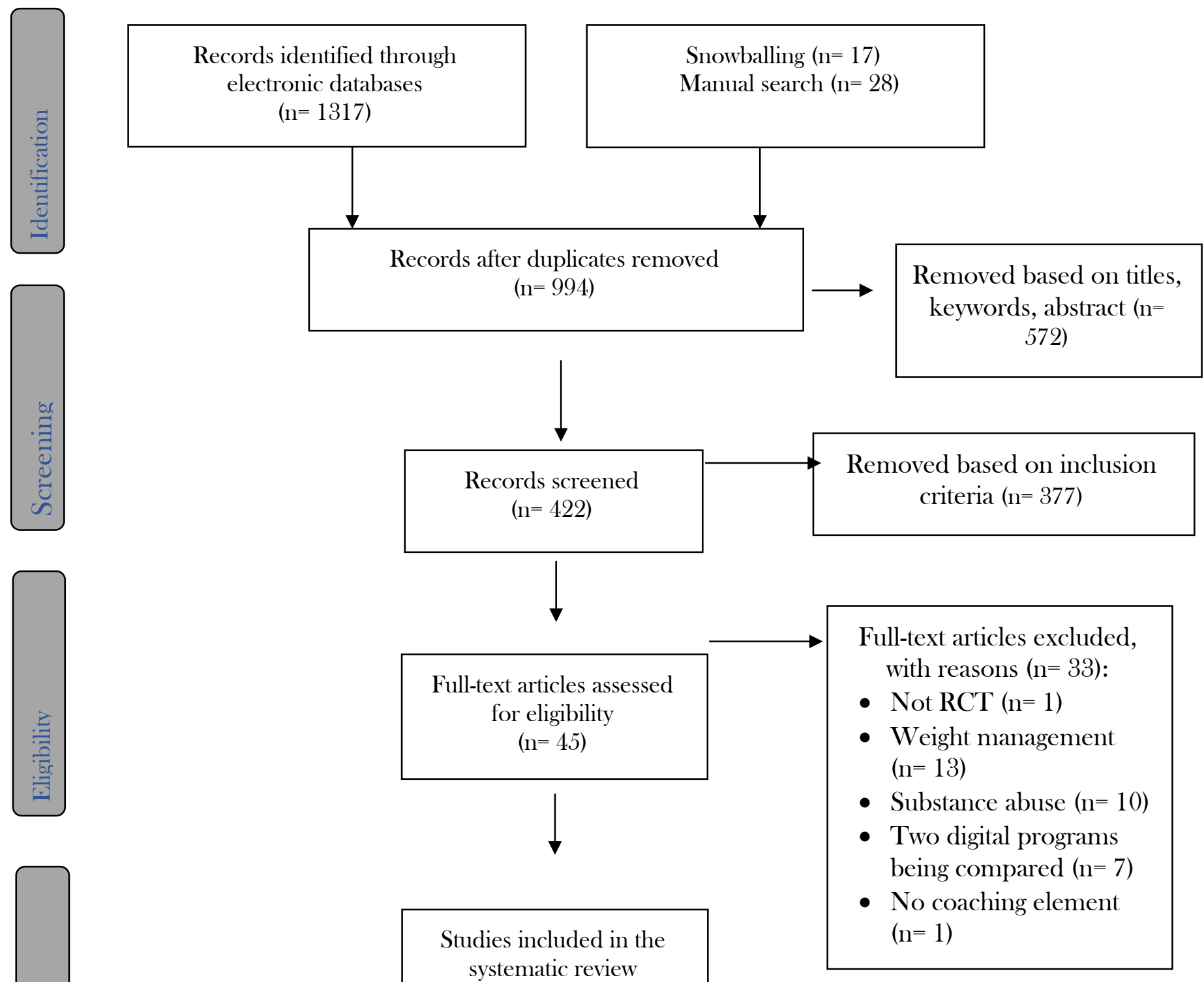

$$
(n=12)
$$




\begin{tabular}{|c|c|c|c|c|c|c|c|c|c|c|c|c|}
\hline \multicolumn{7}{|c|}{ Certainty assessment } & \multicolumn{2}{|c|}{ № of patients } & \multicolumn{2}{|c|}{ Effect } & \multirow[b]{2}{*}{ Certainty } & \multirow[b]{2}{*}{ Importance } \\
\hline $\begin{array}{l}\text { № of } \\
\text { studies }\end{array}$ & Study design & Risk of bias & Inconsistency & Indirectness & Imprecision & Other considerations & $\begin{array}{c}\text { e-coach } \\
\text { intervention }\end{array}$ & $\begin{array}{l}\text { no internet } \\
\text { intervention/ no e- } \\
\text { coaching } \\
\text { intervention }\end{array}$ & $\begin{array}{l}\text { Relative } \\
(95 \% \mathrm{Cl})\end{array}$ & $\begin{array}{l}\text { Absolute } \\
(95 \% \mathrm{Cl})\end{array}$ & & \\
\hline \multicolumn{13}{|c|}{ Transition readiness (follow up: range 8 weeks to 8 months; assessed with: different tools) } \\
\hline 4 a & $\begin{array}{l}\text { randomised } \\
\text { trials }\end{array}$ & not serious & not serious & not serious & serious $^{b}$ & none & 114 & 110 & - & not estimable & $\underset{\text { MODERATE }}{\bigoplus \bigoplus \bigoplus \bigcirc}$ & CRITICAL \\
\hline \multicolumn{13}{|c|}{ Self - management (follow up: range 8 weeks to 1 years; assessed with: several different trools; Scale from: 1 to 100) } \\
\hline 80 & $\begin{array}{l}\text { randomised } \\
\text { trials }\end{array}$ & not serious & serious $^{d}$ & not serious & serious ${ }^{b}$ & none & 371 & 358 & - & not estimable & $\bigoplus \bigoplus_{L O}$ & CRITICAL \\
\hline \multicolumn{13}{|c|}{ Health outcome (follow up: range 6 weeks to 2 years; assessed with: several different tools) } \\
\hline $12 e$ & $\begin{array}{l}\text { randomised } \\
\text { trials }\end{array}$ & not serious & serious ${ }^{d}$ & serious ${ }^{f}$ & not serious & none & 862 & 693 & - & not estimable & $\oplus \bigoplus_{L C}$ & CRITICAL \\
\hline \multicolumn{13}{|c|}{ Self-efficacy (follow up: range 6 weeks to 8 months; assessed with: several different tools) } \\
\hline 59 & $\begin{array}{l}\text { randomised } \\
\text { trials }\end{array}$ & not serious & serious ${ }^{d}$ & not serious & serious ${ }^{b}$ & none & 130 & 124 & - & not estimable & $\bigoplus \bigoplus_{\text {LOI }}$ & CRITICAL \\
\hline \multicolumn{13}{|c|}{ Stress, anxiety (follow up: range 6 weeks to 12 weeks; assessed with: several different measures) } \\
\hline $4^{\mathrm{h}}$ & $\begin{array}{l}\text { randomised } \\
\text { trials }\end{array}$ & not serious & serious $^{d}$ & not serious & serious ${ }^{b}$ & none & 124 & 130 & - & not estimable & $\oplus$ & CRITICAL \\
\hline \multicolumn{13}{|c|}{ Health related quality of life (follow up: range 6 weeks to 1 years; assessed with: Several different QoL measuringtools; Scale from: 0 to 100) } \\
\hline 81 & $\begin{array}{l}\text { randomised } \\
\text { trials }\end{array}$ & not serious & serious $^{d}$ & not serious & serious ${ }^{b}$ & none & 377 & 364 & - & not estimable & $\oplus \oplus_{L}$ & CRITICAL \\
\hline
\end{tabular}

Table 1 GRADE Certainty assessment of transition outcomes.

Question: Should e-coach intervention vs. no internet intervention/ no e-coaching intervention be used for chronically ill adolescents during transition of care?

\section{Cl: Confidence interval}

\section{Explanations}

a. Ammerlaan et al., (2017); Breakey et al., (2014), Huang et al., (2014); Stinson et al., (2016).

b. Small sample size (-1)

c. Ammerlaan et al., (2017); Breakey et al., (2014); Hanberger et al., (2013); Harris et al., (2015); Huang et al., (2014); Rikkers-Mutsaerts et al. (2012); Stinson et al., (2010, 2016).

d. There was a level of inconsistency in the results $(-1)$. This could be explained by differences in outcome measures, timing and heterogeneity of characteristics of interventions.

e. All included studies

f. Some level of Indirectness (-1) this could be explained by heterogeneity of the interventions and measurements; impact of the intervention measured using surrogate measures instead of corresponding patient-important outcomes

g. Ammerlaan et al., (2017); Breakey et al., (2014); Huang et al., (2014); Stinson et al., (2010, 2016)

i. Ammerlaan et al., (2017); Bonnert at al., (2017); Breakey et al., (2014); Hanberger et al., (2013); Huang et al., (2014); Rikkerts-Mutsaerts et al., (2012); Stinson et al., (2010), (20 
Table 2 Characteristics of the interventions.

\begin{tabular}{|c|c|c|c|}
\hline Brief name & Why & When and how much & Who and how provided \\
\hline $\begin{array}{l}\text { 1. "Challenge your } \\
\text { Arthritis" } \\
\text { Ammerlaan et al. } \\
\text { (2017) } \\
\end{array}$ & $\begin{array}{l}\text { - To support young adult's self- } \\
\text { management in coping with JIA. }\end{array}$ & $\begin{array}{l}\text { - } \quad 6 \text { weeks/ } 12 \text { hours, } 6 \text { weekly themes } \\
\text { - } \quad \text { Chat (max } 90 \text { min } 8 \text { weekly } 6 \text { participants/ } 2 \text { trainers }\end{array}$ & $\begin{array}{l}\text { - Web-based, password-protected, self-management program } \\
\text { - } \quad \text { Peer trainers 20-30 years, trained through educational program } \\
\text { - Interactive - three components, chat, home exercises and discussion board. }\end{array}$ \\
\hline \begin{tabular}{|l|} 
2.. "Exposure-based \\
Internet CBT" \\
Bonnert et al. \\
(2017) \\
\end{tabular} & $\begin{array}{l}\text { - To evaluate the efficacy of Internet } \\
\text { delivered cognitive behavioural therapy } \\
\text { (CBT) based on behavioural exposure for } \\
\text { adolescents with Irritable Bowel Disease. }\end{array}$ & $\begin{array}{l}\text { - } \quad 10 \text { weeks. } 10 \text { weekly modules for adolescents, } \\
\text { - } \quad 5 \text { for parents } \\
\quad \text { No mention of duration for completing modules. }\end{array}$ & $\begin{array}{l}\text { - } \quad \text { Five clinical psychologists with CBT training } \\
\text { - } \quad \text { Provided weekly online support and feedback to adolescents and parents. } \\
\text { - } \text { Questions answered within two working days. Text messages and phone } \\
\end{array}$ \\
\hline $\begin{array}{l}\text { 3." Teens Taking } \\
\text { Charge: Managing } \\
\text { Haemophilia } \\
\text { Online" } \\
\text { Breakey et al. } \\
\text { (2014) } \\
\end{array}$ & $\begin{array}{l}\text { - To evaluate the feasibility of an Internet- } \\
\text { based self-management and transitional } \\
\text { care program for adolescents with } \\
\text { haemophilia. }\end{array}$ & $\begin{array}{l}\text { - } 8 \text { weeks. } 8 \text { weekly modules, } \\
\text { - } \quad 30 \text { min each. } \\
\text { - Available in English and French. }\end{array}$ & $\begin{array}{l}\text { - } \quad \text { Password-protected website. } \\
\text { - } \quad \text { Weekly contact by coach. } \\
\text { - Telephone calls were structured using standardized scripts. } \\
\text { - } \quad \text { answered questions and provided guidance. } \\
\quad \text { Difficult questions were redirected to their haemophilia team. } \\
\end{array}$ \\
\hline $\begin{array}{l}\text { 4. "Behavioural } \\
\text { Family Systems } \\
\text { Therapy for } \\
\text { Diabetes" } \\
\text { Freeman et al. } \\
\text { (2013) } \\
\end{array}$ & $\begin{array}{l}\text { - To compare the therapeutic alliance } \\
\text { when behavioural health care was } \\
\text { delivered to youth with poorly controlled } \\
\text { DM1. }\end{array}$ & $\begin{array}{l}\text { - } 12 \text { weeks/ } 10 \text { sessions delivered through Skype or in- } \\
\text { clinic } \\
\text { - } 1-1,5 \text { hours each }\end{array}$ & $\begin{array}{l}\text { - } \quad \text { Therapists followed family systems therapy for Diabetes manual } \\
\text { - } \quad \text { Contact via telephone to arrange appointments or to reschedule } \\
\text { - } \quad \text { No show participants called weekly to reschedule }\end{array}$ \\
\hline $\begin{array}{l}\text { 5. "The Diabit Web } \\
\text { 2.0 portal" } \\
\text { Hanberger et al. } \\
(2013)\end{array}$ & $\begin{array}{l}\text { - To develop a Web } 2.0 \text { portal designed to } \\
\text { facilitate self-management and to study } \\
\text { its use and effects for adolescents with } \\
\text { poorly controlled diabetes. }\end{array}$ & $\begin{array}{l}\text { - } \quad 1-2 \text { years. } \\
\text { - } \quad \text { Designed for use by paediatric patients, parents, and } \\
\text { - } \quad \text { Diabetitioners wheneverer needed by users' own initititive } \\
\end{array}$ & $\begin{array}{l}\text { - Passwords protected portal. For children } 13 \text { years of age and older own } \\
\text { passwords. } \\
\text { - The member of the diabetes team encouraged active self-control and offered } \\
\text { psychosocial support and problem-based education. }\end{array}$ \\
\hline $\begin{array}{l}\text { 6. "Behavioural } \\
\text { Family Systems } \\
\text { Therapy for } \\
\text { Diabetes" } \\
\text { Harris et al. (2015) }\end{array}$ & $\begin{array}{l}\text { - To compare the relative effectiveness of } \\
\text { two models of delivering Behavioural } \\
\text { Family Systems Therapy } \\
\text { - To improve adherence and glycaemic } \\
\text { control in poorly controlled DM } 1 .\end{array}$ & $\begin{array}{l}\text { - } 3 \text { months. } \\
\text { Adolescents and at least one adult caregiver received } \\
\text { Behavioural family systems therapy either via the Clinic } \\
\text { or Skype. Participants completed } 10 \text { therapy sessions } \\
\text { /12-weeks. }\end{array}$ & $\begin{array}{l}\text { - Therapy delivered by clinicians with a master's or doctoral psychology degree } \\
\text { trained in the intervention. } \\
\text { - Therapists and families communicated to establish regular meeting times, } \\
\text { and a research assistant provided reminder calls for upcoming appointments. }\end{array}$ \\
\hline $\begin{array}{l}\text { 7."MD2Me" } \\
\text { Huang et al. (2014) }\end{array}$ & $\begin{array}{l}\text { - To evaluate an 8-month transition } \\
\text { intervention (MD2Me). }\end{array}$ & $\begin{array}{l}\text { - 8-month disease management intervention based on } \\
\text { Bandura's Social Cognitive Theory. } \\
\text { - For } 2 \text { months weekly log-ons to a secure web site. }\end{array}$ & $\begin{array}{l}\text { - Recipients had access to a texting algorithm for disease assessment and } \\
\text { - } \\
\text { - Contacth care team contact. } \\
\text { answer in } 24 \text { hrs. Concerns were relayed to the health care team. } \\
\text { - Tailored short messages, SMS and queries sent to ensure that participants } \\
\text { received and understood interventions. }\end{array}$ \\
\hline
\end{tabular}




\begin{tabular}{|c|c|c|c|}
\hline $\begin{array}{l}\text { 8." Puff City" } \\
\text { Joseph et al. (2013) }\end{array}$ & $\begin{array}{l}\text { - To evaluate Puff City, a Web-based, } \\
\text { tailored asthma intervention. }\end{array}$ & $\begin{array}{l}\text { - } 12 \text { months. } \\
\text { - } \quad \text { mour online asthma management sessions } 15-30 \\
\text { - To be completed in maximum } 180 \text { days, with a } \\
\text { minimum of one week between sessions. } \\
\text { - Computers at school were used by participants. }\end{array}$ & $\begin{array}{l}\text { - A referral coordinator used a risk assessment report generated by the data } \\
\text { management system to proactively contact students. } \\
\text { Computer algorithms use teens responses to select the appropriate } \\
\text { information from a message library and assemble pre-programmed, tailored } \\
\text { feedback. } \\
\text { Referral coordinator guided participants to community agencies and } \\
\text { resources as needed. }\end{array}$ \\
\hline $\begin{array}{l}\text { 9. "Breathe easier } \\
\text { online" } \\
\text { Newcombe at al. } \\
(2012)\end{array}$ & $\begin{array}{l}\text { - To evaluate the efficacy of internet } \\
\text { program, Breathe Easier Online. } \\
\text { To improve social problem-solving skills; } \\
\text { and an online community that had }\end{array}$ & $\begin{array}{l}\text { - } 9 \text { weeks. } \\
\text { - } \quad \text { Five modules; My condition, My page, Daily diary, My } \\
\text { work and My talk } \\
\text { - Synchronous (e-mail or discussion board) and } \\
\text { asynchronous (instant messenger) communication } \\
\text { opportunities. }\end{array}$ & $\begin{array}{l}\text { - Interactive, password protected site with homework and online } \\
\text { communication with research staff and other participants. } \\
\text { Online support group including forums, email facility, and graffiti wall. No chat } \\
\text { facilities. } \\
\text { - Respiratory outpatient clinic at royal Children's Hospital. Brisbane, Australia }\end{array}$ \\
\hline $\begin{array}{l}\text { 10. Internet- based } \\
\text { self -management } \\
\text { (ISBM) } \\
\text { Rikkers-Musaerts et } \\
\text { al. (2012) }\end{array}$ & $\begin{array}{l}\text { - To compare Internet-Based Self- } \\
\text { Management Compared with Usual Care } \\
\text { in adolescents with asthma }\end{array}$ & $\begin{array}{l}\text { 1-year. } \\
\text { - } \quad \text { Web- education and face- to face group, } \\
\text { Four components self-education, self-monitoring, } \\
\text { electronic action plan with weekly assessment, regular } \\
\text { medical review every 3-6 months. } \\
\text { - No mention of duration of sessions. }\end{array}$ & $\begin{array}{l}\text { - } \quad \text { A secure web application with login password. } \\
\text { Interactive communication with a specialized nurse, and face-to-face group- } \\
\text { based education. } \\
\text { Weekly asthma control monitoring with treatment advice by a web-based } \\
\text { algorithm. }\end{array}$ \\
\hline $\begin{array}{l}\text { 11. "Teens taking } \\
\text { charge managing: } \\
\text { Managing arthritis } \\
\text { online" } \\
\text { Stinson et al. (2010) }\end{array}$ & $\begin{array}{l}\text { - To determine the feasibility of an } \\
\text { Internet-based self-management } \\
\text { program of disease-specific information, } \\
\text { self-management strategies, and social } \\
\text { support }\end{array}$ & $\begin{array}{l}\text { - } 12 \text { weeks, } \\
\text { - } 12 \text { online modules and weekly phone calls with a } \\
\text { coach } \\
\text { - } 2 \text { modules for parents. } \\
\text { - } 20 \text { - } 30 \text { minutes. }\end{array}$ & $\begin{array}{l}\text { - } \quad \text { Logged on to a restricted website } \\
\text { - } \quad \text { in psined coach, a non-health- care professional with an undergraduate degree } \\
\text { - } \quad \text { Coach reviewed, quizzes, and personal goals made by the adolescents, } \\
\text { provided guidance, monitored discussion boards and postings daily. } \\
\text { - The coach redirected difficult questions to a specialist in rheumatology. }\end{array}$ \\
\hline $\begin{array}{l}\text { 12. "iPeer2Peer } \\
\text { program" } \\
\text { Stinson et al. (2016) }\end{array}$ & $\begin{array}{l}\text { - To examine the feasibility and } \\
\text { acceptability of an online peer mentoring } \\
\text { program iPeer2Peer Program for } \\
\text { adolescents with JIA. }\end{array}$ & $\begin{array}{l}\text { - } 8 \text { weeks } \\
\text { - } \quad 10 \text { sessions of } 20-30 \text { min. } \\
\text { Participant-mentor pairings had two sessions per week } \\
\text { for the first two weeks, and one session per week for } \\
\text { six weeks. }\end{array}$ & $\begin{array}{l}\text { - } \quad \text { Trained peer mentors (16-25 years) matched with participants. } \\
\text { - } \quad \text { Mentors trained to flag concerns (e.g. self-harm) that needed help by a } \\
\text { member of the research team. } \\
\text { To ensure safety, a member of the research team reviewed all calls within } 48 \\
\text { h. } \\
\text { - Peers function as positive role model, reinforced self- efficacy, self- } \\
\text { management skills and social support. }\end{array}$ \\
\hline
\end{tabular}




\begin{tabular}{|c|c|c|c|c|c|c|c|c|c|c|c|c|c|c|c|}
\hline \multirow[b]{2}{*}{ Coaching elements } & \multicolumn{4}{|c|}{ Human support } & \multicolumn{5}{|c|}{ Interactive means } & \multicolumn{3}{|c|}{ Social support } & \multicolumn{3}{|c|}{ Theoretical basis } \\
\hline & $\begin{array}{l}\bar{c} \\
\text { s̆ } \\
\text { s. }\end{array}$ & 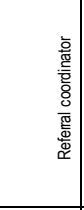 & 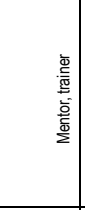 & 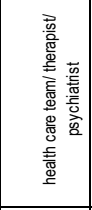 & 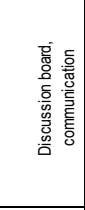 & 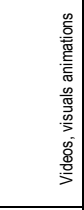 & 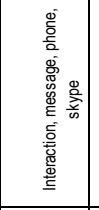 & $\overline{\mathrm{g}}$ & 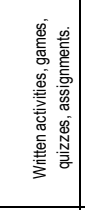 & 善 & $\stackrel{\overline{\$}}{\square}$ & 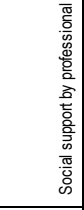 & 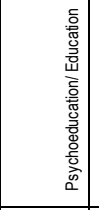 & 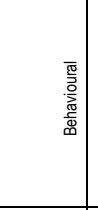 & \\
\hline 1. Ammentaan etal. (2017) & + & + & $\oplus$ & $\oplus$ & $\oplus$ & $\oplus$ & $\oplus$ & 0 & 0 & & 0 & 0 & 0 & & \\
\hline 2. Bonnet te tal. (2017) & & & + & 0 & & + & $\oplus$ & O & 0 & 0 & & 0 & 0 & 0 & \\
\hline 3. Breakey et tal. (2014) & + & + & + & + & + & + & + & 0 & 0 & & 0 & O & & & \\
\hline 4. Freeman etal. (2013) & & & + & $\oplus$ & 0 & & 0 & O & & 0 & & O & $O$ & 0 & \\
\hline 5. Hanbergeretal. (2013) & & + & + & 0 & 0 & 0 & + & & & O & 0 & 0 & 0 & & \\
\hline 6. Haris etal. (2015) & & + & + & 0 & 0 & & 0 & 0 & & 0 & & 0 & 0 & & \\
\hline 7. Huang et al. (2014) & + & + & + & 0 & $\oplus$ & + & + & & 0 & & & 0 & & & 0 \\
\hline 8. Joseph tatal. (2013) & & 0 & + & + & & 0 & 0 & 0 & 0 & & & 0 & & 0 & \\
\hline 9. Newcombe etal. (2012) & & & + & † & & + & 0 & & 0 & $\bigcirc$ & 0 & O & & 0 & O \\
\hline 10. Rikkers-Musaerts etal. (2012) & & + & + & + & & & $\oplus$ & & 0 & & & O & 0 & & \\
\hline 11. Stinson etal. (2010) & 0 & + & + & $\oplus$ & $\oplus$ & + & $\oplus$ & 0 & 0 & 0 & & 0 & & & \\
\hline 12. Stinton et al. (2016) & + & + & + & + & + & & + & & & 0 & O & 0 & & & \\
\hline Transition elements & 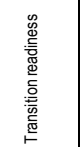 & 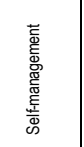 & $\begin{array}{l}\text { 产 } \\
\text { 言 } \\
\text { 高 } \\
\text { I. }\end{array}$ & 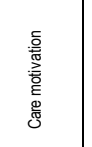 & 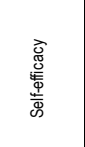 & 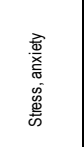 & 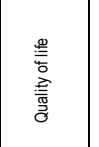 & & & & & & & & \\
\hline
\end{tabular}

Table 3 Coaching and Transition elements. 